\title{
Assessment of predictive value of admission criteria of candidates for pharmaceutical studies - an empirical investigation
}

\author{
Mariusz Panczyk*, Henryk Rebandel, Joanna Gotlib \\ Division of Teaching and Outcomes of Education, Faculty of Health Sciences, Medical University of Warsaw, Poland.
}

\begin{abstract}
Aim: Assessment of predictive value of results of maturity exams applied as admission criteria for pharmaceutical studies at the Medical University of Warsaw (MUW) between 2010-2012. Material and methods: Data of 390 students who began their studies and completed their first year of full-time studies at the pharmaceutical department of MUW. Admission data included: total score gained by a candidate, score concerning biology, chemistry and mathematics. Results in three subjects included in the first year studies curriculum were assessed (Anatomy, Biology with genetics and Pharmaceutical Botany) and a grade point average (GPA) covering this period of time. In order to perform predictive assessment, the analysis of correlation was applied as well as multiple regressions. Results: A model of the function of regression in form of: GPA $=0.012 \cdot$ (total ranking points) $-0.234 \cdot$ (gender) explains sufficiently the changeability of results obtained by students after their first year of studies $(F=14.984$ $P<0.000001)$. The results of analysis point out that indeed men have lower chances of achieving a higher GPA after their first year than women $(\beta=-0.156)$. Moreover, GPA value prediction after the first year of studies shows that for every additional ranking point achieved during recruitment, the increase in score is on average 0.236 . Conclusion: The total of ranking points achieved by a candidate accepted to pharmaceutical studies is of significance when considering educational outcomes obtained after the first year of studies. Mastering the system of accepting candidates to university may lower the failure rate among the students of a difficult and demanding major such as pharmaceutical one.
\end{abstract}

Key words: Performance, Admission criteria, Output variable, academic progression, pharmacy education.

\section{INTRODUCTION}

According to the stipulations of the Act of 27 th July 2005, Law on Higher Education (Journal of Laws, 2005 No 164 item 1365) in Poland the system of accepting candidates to pharmaceutical full-time studies is based on the selection process carried out on the grounds of the results of national maturity exam - high-school exit exams (equivalent of A-levels in UK, Baccalauréat in France or Abitur in Germany). Under Article 169 paragraph 3 of this Act," Senate of the University establishes (...) what score of the maturity exam become the bases of being accepted to the university". The result of maturity exam obtained by a candidate is the basis of applying for a place at one of ten Pharmaceutical Departments. ${ }^{1}$ Majority of medical universities who educate wouldbe pharmacists requires their candidates to present the results in maturity exam on extended level in chemistry and biology. Moreover, Medical University of Warsaw (MUW) introduced in 2010 an additional criterion based on the results of maturity exam in mathematics.

Universities educating pharmacists ought to introduce such admission policy that would guarantee the selection of the best candidates for this responsible profession. Commonly accepted in Poland strategy of selecting candidates is based solely on cognitive skills criteria of assessment which in
Submission Date :05-01-2015 Revision Date : :16-01-2015 Accepted Date : :19-01-2015

DOI: 10.5530/ijper.49.2.6 Correspondence Address Mr. Mariusz Panczyk Division of Teaching and Outcomes of Education, Faculty of Health Science, Medical University of Warsaw, Zwirkii Wigury61, 02-091 Warsaw, Poland, E-mail:mariusz.panczyk@ wum.edu.pl

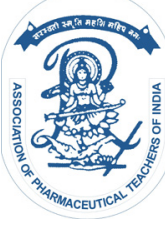

www.ijper.org 
relation to the results of education research accessible in worldwide literature may become a subject to criticism. ${ }^{2}$ Lack of assessment of non-cognitive attributes of candidates may contribute to a worse prediction in terms of appropriate assessment of future success that may be achieved throughout the process of studies as well as future career of the graduates of a given major. ${ }^{3-6}$ Despite this fact, solutions similar to the one applied in Poland, may be found in other countries, which is an intermediate solution between a strategy of selecting candidates who fulfil specific predispositions in the cognitive and non-cognitive area, and the admission policy according to which it is only after the first year that we perform the actual selection of students for a given major. $^{7}$

Every year, about 120 graduates of full-time pharmacy studies leave MUW and the number of attrition among the students in recent years has oscillated between $15-20 \%$. Selecting the reliable and valid criteria of selection allows better assessment of chances that students have and their assumed education outcomes, and among graduates the possibility of achieving success in their profession. Taking care of high standards of teaching and effective teaching in a profession as important as a pharmacist / chemist, ought to go hand in hand with permanent control of mechanisms of selection of candidates for this major. Improper selection of criteria contributes greatly to significant increase in the ratio of attrition among the perspective students. Even the best systems ensuring the quality of education will not fulfil their role if a group of students will not be able to come up to the expectations due to the lack of certain features and predispositions that had not been properly assessed during educational diagnosis and verified during the process of admission to academic institutions.

In accessible literature, plenty of space has been devoted to evaluation of various factors that may affect the effectiveness of pharmacy studies. ${ }^{3-5,8-18}$ Among the predicators that have been selected (the explanatory variables), the authors most frequently list the following: average from high school (GPA, grade point average), results of an interview, ${ }^{4}$ score from various standardised tests California Critical Thinking Skills Test (CCTST), Health Sciences Reasoning Test (HSRT) and Pharmacy College Admission Test (PCAT). ${ }^{8,11}$ For predictive analysis to be appropriate, the selected explanatory variables (independent ones) should assess these competences which are of direct influence on achieving success by a student of a graduate of pharmaceutical studies. Whereas most frequent explanatory variables (dependent ones) in correlation analyses and analyses of multi-regression are the following: score obtained by a student after the first year of studies, ${ }^{15,16,19,20} \mathrm{GPA}$ value that includes biomedi- cal subjects, grades in subjects connected with pharmaceutical science, results of tests in pharmacology and pharmacotherapy, GPA value in practical classes and internship, and the result of exam for the profession, such as, e.g. North American Pharmacist Licensure Examination Test (NAPLEX). ${ }^{3,12}$ Predictive research concerning efficiency of the process of selection of candidates for pharmaceutical studies mostly apply, as a dependent variable that is a measure of success, GPA value achieved by a student after the first year. ${ }^{15,16,19,20}$ Educational outcomes in the first two semesters are thought to be an indicator of to what extent a student adjusted to the discipline of studying at university.

Educating pharmacists in Poland is performed within full-time MA studies and lasts for five and a half years that is 10 semesters at university and one additional mandatory internship at a chemist, leading to obtaining the pharmacist licensure examination. ${ }^{21}$ Within the curriculum in the first two semesters students of the Pharmacy Department at MUW are educated in 12 subjects (and PE), four of which culminate in an exam: Anatomy, Biology with genetics, Pharmaceutical Botany and Generall Inorganic Chemistry. The first three of the listed subjects become the basis for further education in biomedical science such as physiology, pathophysiology and biochemistry. This thematic block is a key one for the proper understanding of mechanisms of drug action and the practical application of medical substances in pharmacotherapy, which is the subject of education in Pharmacodynamics and Biopharmacy in further years of studies. Because knowledge and science as well as basic skills in the area of biomedicine are of essence in shaping the key competences of future pharmacists, ${ }^{22}$ it may be assumed that it will be a relevant dependent variable in predictive assessment.

The aim of this study was to assess the predictive value of the results of maturity exams that are applied as admission criteria for pharmacological studies at MUW between 2010-2012.

\section{MATERIAL AND METHODS}

Data of 390 students who began their studies and completed the first year of full-time studies at Pharmacy Department at MUW were used in the study. This group accounted for $85 \%$ of all students accepted for the first year of studies. Average age of the studied group was $19.2 \pm 0.51$. Moreover, a vast majority among the studied subjects was women (84.4\%). Three of the analysed years were compared according to gender and the structure of age (Table 1).

Admission data was used in analysis including a total score obtained by a candidate accepted for the pharma- 
Table 1: Characteristic of a studied group of students who began their

studies between 2010-12 and completed their first year of education at MUW

\begin{tabular}{|c|c|c|c|c|c|}
\hline & Mean age \pm SD & P-value* & $\mathbf{N}$ & $\begin{array}{c}\% \\
\text { women }\end{array}$ & P-value ** \\
\hline 2010 & $19.0 \pm 0.18$ & \multirow[t]{4}{*}{0.095} & 130 & $87.7 \%$ & \multirow[t]{4}{*}{0.401} \\
\hline 2011 & $19.3 \pm 0.55$ & & 143 & $81.8 \%$ & \\
\hline 2012 & $19.3 \pm 0.63$ & & 117 & $83.8 \%$ & \\
\hline Total & $19.2 \pm 0.51$ & & 390 & $84.4 \%$ & \\
\hline
\end{tabular}

SD - standard deviation

* ANOVA Kruskal-Wallis test applied for comparison of age structure of candidates

$* *$ Chi2 Pearson test applied for comparison of equinumerosity of groups of candidates

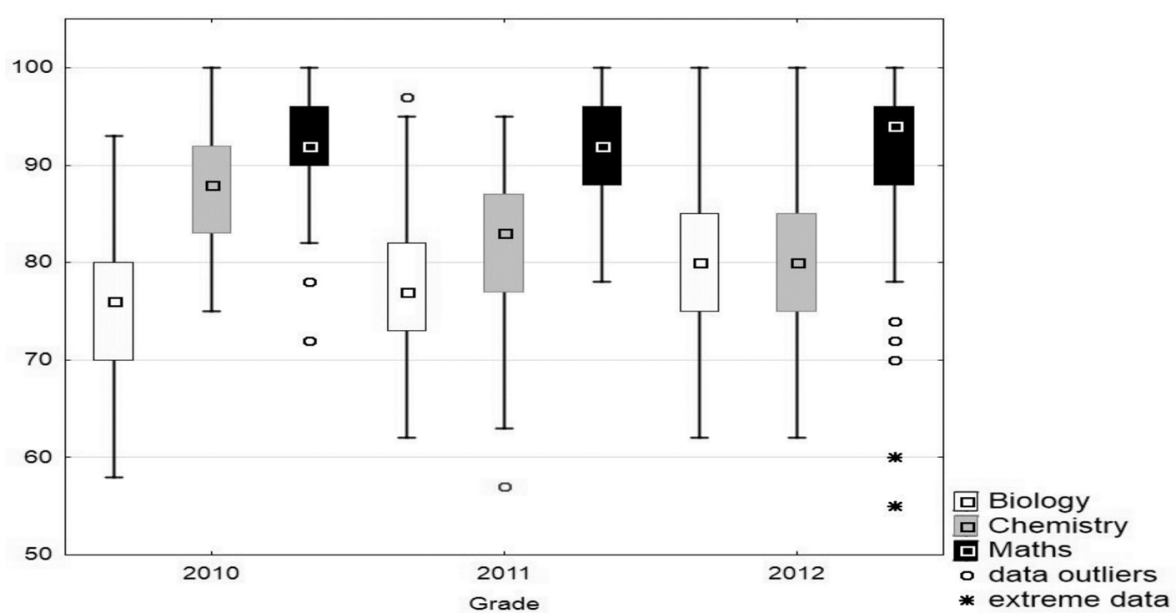

Figure 1: Box and whisker plot for the results obtained by candidates in the area of biology, chemistry and mathematics in three consecutive years. Boxes placed centrally represent median and rectangles interquartile range (25\%-75\%). Graphs also present extreme and outliers data

ceutical studies together with a listed individual score in biology, chemistry and mathematics. Moreover, also three subjects were evaluated which were included in the curriculum of the first year: Anatomy, Biology with genetics, and Pharmaceutical Botany.

Comparing the results of recruitment for individual years and evaluation in three subjects of the first year performed with the use of non-parametric KruskalWallis ANOVA test. Whereas comparing groups of men and women in respect of maturity exams and GPA after the first year of studies was performed using a nonparametric U Mann-Whiney test. In order to perform an inter-correlation test of results obtained by a candidate in biology, chemistry and mathematics, an r-Pearson linear correlation coefficient was used. Moreover, in order to assess mutual correlations between scores for each admission criterion and scores obtained throughout the first year of studies, a rang-Spearman correlation coefficient was established. So as to determine predictive ability of recruitment results, a multiple regression model was applied. For the proposed model, as explanatory variables, a total ranking score was accepted and the candidate's gender, whereas GPA value obtained after the first year of studies became the dependable variable.
Regression function parameters were assessed as well as evaluation of standard errors, and standardised $\beta$ coefficient was established so as to determine the influence of the explanatory variables on the average of grades. A verified form of the regression model was used in evaluating relative progress the students made by determining educational added value.

In calculations, STATISTICA 12.0 (Stat Soft, Inc.) was used according to MUW licence. For all analyses, the relevance level assumed a priori was $a=0.05$.

\section{RESULTS}

Equivalence of the maturity exam was established for each of the three subjects for the analysed years. By comparing the score in mathematics in consecutive years, it appeared that results for this subject obtained by candidates are very similar (ANOVA Kruskal-Wallis: $\mathrm{H}=2.242, P=0.326)$. Whereas in case of biology and chemistry, statistically relevant differences were observed for consecutive years (ANOVA Kruskal-Wallis, respectively: $\mathrm{H}=13.521 P=0.0012 ; \mathrm{H}=70.861 P=0.00001)$. Juxtaposition of the results of comparison of individual admission criteria for the three analysed years was presented in Figure 1. 


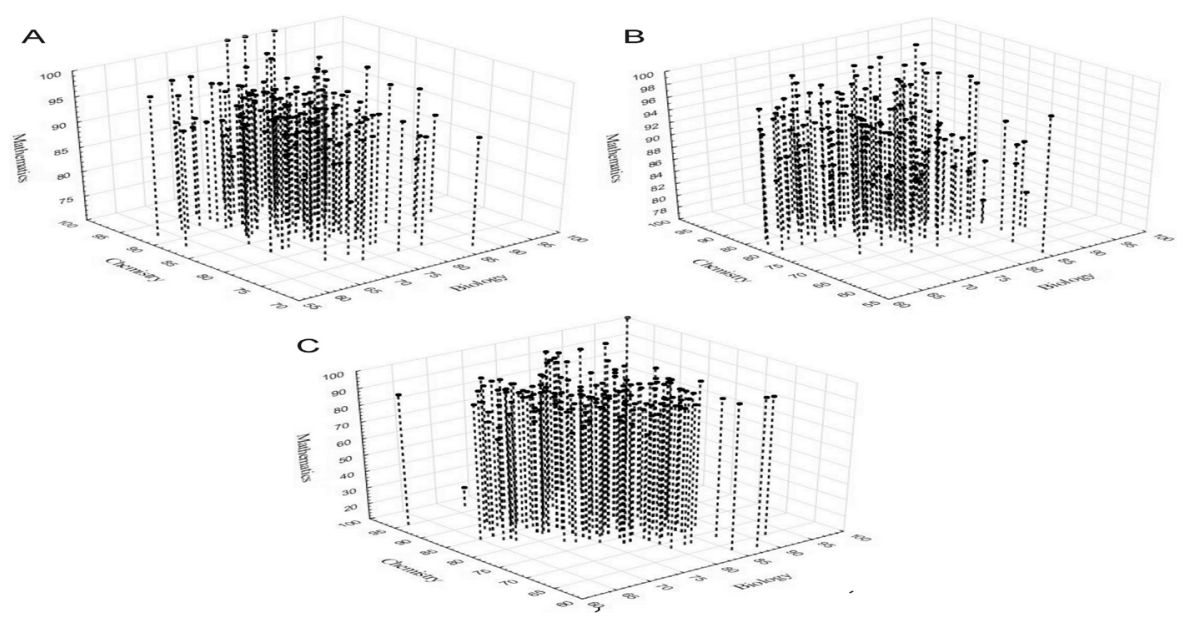

Figure 2: Inter-correlations between the score result for three admission criteria: biology, chemistry and mathematics. Scatter plots represent dependence between the candidates' results in mathematics contrasted with biology and chemistry for the years: A - 2010, B - 2011 and C - 2012

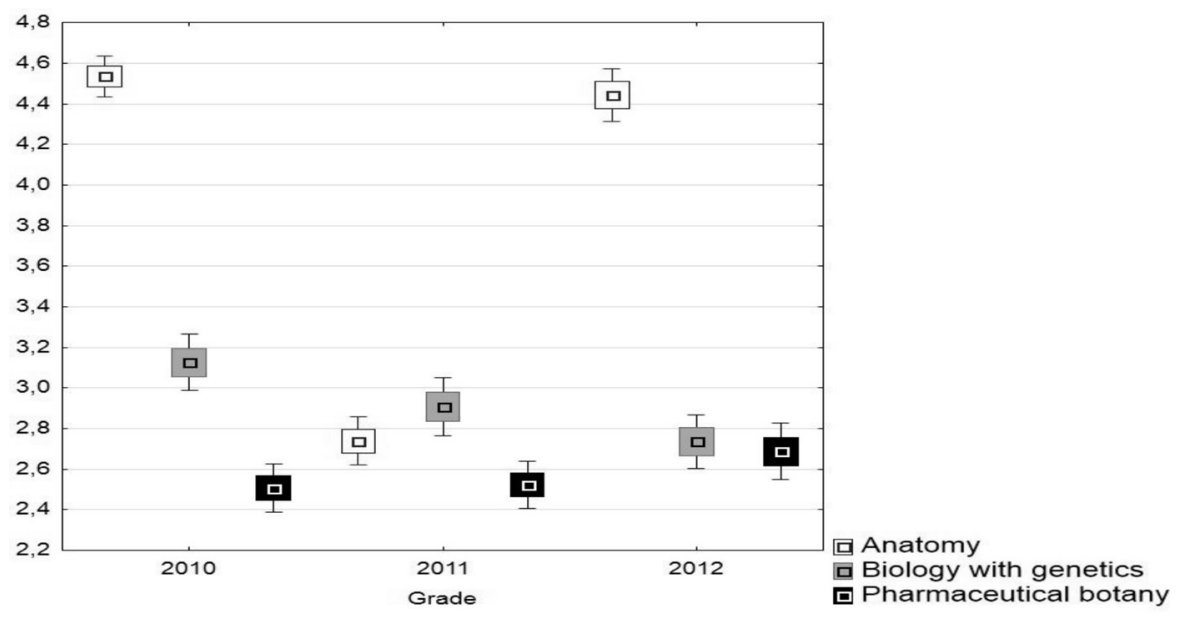

Figure 3: Juxtaposition of results obtained by students in three subjects that culminated in exams in the first year: Anatomy, Biology with genetics and Pharmaceutical botany. Boxes that were placed centrally refer to an average grade; rectangles represent a standard error and whiskers $95 \%$ interval for mean

While analysing differentiation in the results obtained by men and women in the maturity exam in biology, chemistry and mathematics, no statistically relevant differences were found (U Mann-Whitney P>0.05). Whereas GPA comparison performed by the end of the first year of studies showed that women achieved a much higher GPA value than men (GPA median 3.17 vs 3.00; U MannWhitney $=8038.0 P=0.01)$.

Analysis of inter-correlation between score achieved by candidates in three admission criteria for consecutive years showed that for some combinations of subject pairs, there are statistically relevant negative correlations measured by the value of r-Pearson coefficient. For the years 2010 and 2011 such a negative correlation was observed in case of biology - mathematics (r-Pearson was: -0.27 and -0.19 respectively). Moreover, in the years 2011 and 2012 negative correlations were established for biology-chemistry (r-Pearson -0.22 and -0.29 respectively). For none of the studied years no statis- tically relevant correlations were obtained between the candidates' in mathematics and chemistry. Juxtaposition of the results of inter-correlation analysis for the three analysed subjects was presented in Figure 2.

Comparing the grades obtained by students in three subjects culminating in an exam in the first year of studies shows that only in case of Pharmaceutical botany, equivalence is remained in consecutive years (ANOVA Kruskal-Wallis: $\mathrm{H}=4.368 P=0.1126$ ). Whereas in case of Anatomy and Biology with genetics, consecutive years present great deviations in the mean of grades obtained by students in these subjects (ANOVA Kruskal-Wallis, $\mathrm{H}=225.012 P=0.0001 ; \mathrm{H}=14.261 \quad P=0.0008$ respectively). Juxtaposition of equivalence analysis of the three subjects from the first year of studies was presented in Figure 3.

Analysis of correlation between individual criteria of candidates' selection: biology, chemistry, mathematics and the total sum of ranking score, and the results obtained by 
Table 2: Values of correlation r-Spearman coefficients for the analysis of connection

between a candidate's score and individual admission criteria, and results obtained by the student in the first year of pharmaceutical studies

\begin{tabular}{|c|c|c|c|c|}
\hline \multirow[t]{2}{*}{ Grade } & \multirow{2}{*}{$\begin{array}{l}\text { Admission } \\
\text { criteria }\end{array}$} & \multicolumn{3}{|c|}{ Subjects culminating in an examination } \\
\hline & & Anatomy & $\begin{array}{c}\text { Pharmaceutical } \\
\text { botany }\end{array}$ & $\begin{array}{l}\text { Biology with } \\
\text { genetics }\end{array}$ \\
\hline \multirow[t]{4}{*}{2010} & Biology & 0.013 & $0.215^{*}$ & 0.031 \\
\hline & Chemistry & 0.006 & 0.124 & -0.071 \\
\hline & Maths & 0.044 & 0.132 & -0.018 \\
\hline & Total scores & -0.015 & $0.288^{*}$ & 0.001 \\
\hline \multirow[t]{4}{*}{2011} & Biology & -0.061 & 0.103 & -0.054 \\
\hline & Chemistry & $0.177^{*}$ & $0.269^{*}$ & -0.060 \\
\hline & Maths & -0.008 & -0.017 & -0.013 \\
\hline & Total scores & 0.022 & $0.265^{*}$ & -0.091 \\
\hline \multirow[t]{4}{*}{2012} & Biology & -0.072 & 0.051 & -0.012 \\
\hline & Chemistry & -0.045 & 0.151 & 0.073 \\
\hline & Maths & 0.140 & -0.106 & 0.133 \\
\hline & Total scores & 0.020 & 0.031 & $0.195^{*}$ \\
\hline
\end{tabular}

*P-value $<0.05$

Table 3: Statistical parameters of the model of regression for explanatory variables: total ranking score and gender, and the dependent GPA variable after the first year of pharmaceutical studies

\begin{tabular}{|c|c|c|c|c|c|c|c|c|}
\hline \multicolumn{2}{|c|}{ Intercept } & \multicolumn{3}{c|}{ Total score of ranking points } & \multicolumn{3}{c|}{ Gender } \\
\hline $\mathbf{b}_{\mathbf{0}}$ & SE & $\mathbf{b}_{1}$ & SE & $\boldsymbol{\beta}$ & $\mathbf{b}_{\mathbf{2}}$ & SE & $\boldsymbol{\beta}$ & \\
\hline 0.044 & 0.648 & 0.012 & 0.003 & 0.236 & -0.234 & 0.074 & -0.156 & \pm 0.527 \\
\hline
\end{tabular}

bo - intercept of regression model; b1,2-regression coefficients; SE - standard error; $\beta$-standardized coefficient (beta coefficient); SEE - standard error of the estimate;

\section{Table 4: Assessment of relative progress of students of the first year of pharmaceutical studies between 2010-} 12

\begin{tabular}{|c|c|c|c|c|c|c|c|}
\hline \multirow{2}{*}{$\begin{array}{c}\text { Intervals for the } \\
\text { relative value } \\
\text { added }\end{array}$} & $\begin{array}{c}\text { Assessment } \\
\text { of relative } \\
\text { progress }\end{array}$ & $\mathbf{N}$ & $\%$ & $\mathbf{N}$ & $\%$ & $\mathbf{2}$ & Total \\
\cline { 3 - 7 } & Little & 0 & 0 & 0 & 0 & 0 & 0 \\
\hline$=-1.5$ & Below average & 37 & 9.5 & 31 & 9.5 & 6 & 9.8 \\
\hline$(-1.5)-(-0.6>$ & Average & 252 & 64.6 & 213 & 64.7 & 39 & 64.0 \\
\hline$(-0.6)-(+0.5>$ & Above average & 100 & 25.6 & 84 & 25.5 & 16 & 26.2 \\
\hline$(+0.5)-(+1.5>$ & High & 1 & 0.3 & 1 & 0.3 & 0 & 0 \\
\hline$>+1.5$ & & & & & & 0 \\
\hline
\end{tabular}

students in their first year, point to the existence of weak dependencies. Statistically relevant correlations measured by the value of r-Spearman coefficient, concern Pharmacentical botany in the majority of cases. Details of the correlation analysis were juxtaposed in Table 2.

In order to perform a more detailed assessment of a connection between the results of admission for pharmaceutical studies and grades obtained during the first year of studies, a multiple regression analysis was performed. As presented in Table 3, the suggested model of regression function took the form of $G P A=0.012$ - (total ranking score)-0,234. (gender), which explains the changeability of results obtained by students in the first year of studies at pharmaceutical department to a satis- factory level $(\mathrm{F}=14.984 P<0.000001$; standard estimation error $=0.527$ ). Results of regression analysis show that men have statistically lower chances of obtaining a higher mean in exams after the first year than women (standardised coefficient $\beta=-0.156$ ). Moreover, prediction of GPA value after the first year of studies shows that for every additional ranking point obtained during recruitment, there falls an increase in the mean by 0.236 . Additionally, educational added value assessed on the basis of a regression model equation shows that evaluation of relative progress on at least a medium level is presented by $90 \%$ of students. Also, no relevant gender differences were observed in the level of educational added value achieved by the end of the first year (Table 4). 


\section{DISCUSSION}

Medical universities that educate pharmacists enable acquiring skills that are unique and necessary and which are not present in other training programmes. However, for the future student to be able to endure the learning process at the pharmacy department, high initial requirements should be set, which allows the selection of the best candidates who present the appropriate features and predispositions. Appropriate admission system should ensure the selection of those candidates for whom there is a high probability of future career success.

In Poland, both before the year 2005 when the old form of maturity exam was in force and now, the basis on which a candidate was accepted to pharmaceutical department, were results obtained in knowledge and skills in biology and chemistry. There are no perennial or multi-centre prospective studies concerning predictive value of the applied selection criteria. In literature there are numerous results published which relate to the analysis of criteria of acceptance to pharmaceutical colleges. However, a vast majority of them concerns studies carried out in the USA. ${ }^{3-5,8-17,19,20,23-40}$

Extensive experience in tests in an entry exam to pharmaceutical colleges (PCAT) that has been carried out in the USA since 1974 and its spread (about 50\% of all American colleges applies this admission tool), enabled to analyse a number of predictive factors that allow to forecast the future of students during their educational process. ${ }^{3,34,36}$ Requirements set during the selection of candidates for pharmaceutical colleges in the USA are mostly based on the assessment of their knowledge and skills in the field of chemistry, biology, physics and mathematics, but also on their ability to analyse a text, solve problems or critical thinking., ${ }^{34}$ Data that is accessible and come from observations carried out in the USA, based on GPA from high school and the results of PCAT entry exam is an excellent prognostic for the future successes achieved by students. ${ }^{3,5,11,12,25,27,32,38}$

In this work, the authors have attempted answering the question whether criteria of selection accepted at MUW are of predictive value in forecasting the students' future. The obtained results are generally in agreement with the findings of other authors that the total of ranking points of a candidate is positively correlated with the GPA value obtained by a student by the end of the first year of studies at the pharmaceutical department. This main observation remains in accordance with the results of studies carried out at colleges in the USA. ${ }^{11,14,15,34}$ Kuncel et al. ${ }^{11}$ in their meta-analysis published in 2005, found that the sum of points obtained in the PCAT entry exam is positively correlated with the GPA value after the first year of studies (r-Pearson calculated from the sum of 22 studies was $0.45 ; 90 \%$ confidence interval between 0.32 and 0.68 ). Similar results of analysis were also obtained in case of correlations studied for individual elements of PCAT: biology $(\mathrm{r}=0.39)$, chemistry $(\mathrm{r}=0.45)$ and mathematics $(\mathrm{r}=0.47)$. Moreover, several of the later studies carried out by Meagher et al. ${ }^{14,15,34}$ confirm the above values of correlation coefficients, both for the overall PCAT result and its individual elements. It also should be stressed that in case of GPAs calculated after the second, thirds and fourth year of studies, similar results of correlation analysis were obtained; however, r-Pearson coefficient values for consecutive years of studies had a decreasing tendency. ${ }^{11,14}$

One of the relevant elements of predictive assessment is analysis of mutual inter-correlations between independent variables, i.e. individual criteria of selection. Analysis of inter-correlation results for three subjects: biology, chemistry and mathematics show that the areas of evaluated competences using these criteria of selection differ between each other. This is reflected in the negative inter-correlations between subjects: biology-mathematics and biology-chemistry. The above results are contradictoried $^{34}$ that analysed inter-correlations of individual elements of PCAT. Assessing the internal accuracy of the PCAT exam through establishing mutual correlations for biology and chemistry allowed to prove a significant degree of dependence between the results in both these fields obtained by the examinee $(r$-Pearson $=0.60) .{ }^{34}$

The negative correlations that were observed allow claiming that the score obtained by candidates in individual maturity subjects, which is required during the recruitment process, mirrors the assessment of various types of knowledge and skills of candidates, thus the negative correlations.

Confirming the above assumption requires, however, an in-depth analysis of the problem of accuracy of the maturity exam measurement. Nationwide data obtained from the regression analysis concerning correlation between the results of a junior high school exam in maths and biology subjects (GMP) and the results of maturity exams in extended biology and chemistry as well as basic mathematics. A positive dependence between the results obtained by students was demonstrated in the GMP exam in 2002 and the maturity score in 2005. This dependence, measured using a standardised $\beta$ coefficient, was $0.435,0.451$ and 0.514 for biology, chemistry and mathematics respectively. ${ }^{41}$ Similar $\beta$ values indicate a comparable accuracy of the maturity exam score in these three subjects in 2005. What is not obvious, however, is the fact whether or not similar scores would be obtained for the consecutive years. Assumption of various ranges concerning the accuracy in the assess- 
ment of candidates' skills for the three criteria that are the basis when accepting candidates to pharmaceutical studies finds no sufficient confirmation in the data from the analysis of the maturity exam, subject to them concerning other years of students. If we treat three criteria of selection as an overall measurement of education, then the low level of mutual correlations becomes evidence of insufficient criterion-related validity of such an assessment. ${ }^{42,43}$

While analysing score obtained by candidates in individual years, it was observed that only in case of mathematics the results were similar, whereas for biology and chemistry statistically relevant changeability in score was observed. In case of biology, we may observe that in the group of accepted candidates, the score has an increasing tendency, whereas for chemistry this tendency decreases. A cut-off point of accepted / not accepted was placed on a shoulder of a curve determined for chemistry and on a shoulder of a descending curve for biology, which means that both these subjects significantly differed in their level of difficulty for the candidates. Candidates' grades in biology are close to their score in mathematics, whereas a reversed regularity can be observed in case of chemistry. The above observations concern only a three-year period, therefore it is necessary to continue such analyses in consecutive years in order to establish the actual tendencies in terms of correlation and changeability of candidates' score for pharmaceutical studies. No stability in the field of scoring for individual subjects in consecutive years makes it difficult for the predictive analysis of the entry exam to be performed because summarising the scores for different years bears an error of large inter-group changeability. Therefore, in the strategy of correlation analysis assumed for this work, individual years of students were assessed separately.

The correlation analysis of individual criteria of the candidates' selection shows that subject ranges that are the basis of admission for pharmaceutical studies are not consistent with the results of teaching for individual subjects in the area of biomedical sciences. The best results in this area were obtained for the subject of Pharmaceutical botany. This is also the only subject out of those studied in the first year of studies, for which consistency of scoring was presented in individual years. It may be assumed that the assumed principles of assessment for this subject have consequently been applied in consecutive years. Assuming that the maturity exam on extended level ensures an accurate measurement of knowledge and skills of the graduates of high schools, it may also be assumed that positive correlations with the results of teaching in the subject of Pharmaceutical botany confirms the accuracy of the assessment of a candidate's predispositions in the area of biological sciences. Moreover, it may also be assumed that the applied methods of didactic measurement for this subject accurately assess students' competences in the area of Pharmaceutical botany. Lack of or low level of such a correlation for other subjects may become evidence of non-compatibility of selection criteria with the specific needs of candidates' assessment or that the evaluation system for these subjects does not provide an accurate measurement.

Due to the fact that accepting linear correlation r-Pearson or rang-Spearman as an assessment index is a simplified model, more credible results may be obtained using regression analysis in predictive studies. Such approach assumes that success achieved by a student throughout the course of studies is conditioned by more than one predictive factor. According to evidence available in literature, GPA value obtained by a student after the first year of studies in order to determine the level of success. ${ }^{15,16,19,20}$ For this dependent variable, a regression model with two independent variables was suggested: a total score of ranking points and the candidate's gender Meagher et al. ${ }^{14}$ found that the mean of grades obtained by a student after the first year of studies may be predicted to a large extent on the basis of the PCAT, although also GPA value from high school should be included in the regression model. Moreover, the authors of this study observed that individual subject ranges included in the PCAT also are of high predictive value, although lower than the total score. ${ }^{14}$ Chisholm et al. ${ }^{20}$ showed that GPA value from sciences taught at high schools is a strong independent predictive factor. A similar dependence was found by McCall et al., ${ }^{33}$ however, this time it was related to the score obtained by a candidate in extended biology. The results of regression analysis presented in this work partly confirm the above observations. Standardised $\beta$ coefficient on the level of 0.236 shows that the total score of ranking points is a predicator for the mean of a student's grades after the first year of studies in the Pharmacy Department. No relevant predictive impacts of individual selection criteria were observed, however. This is probably related to the lack of positive inter-subject inter-correlations that was described above.

Several multiple regression analyses that were carried out as important predicators, were included into the model of demographic variables such as: age, gender, and type of completed high school or parents' education. ${ }^{10,15,19,20,24,39}$ The relevant dependencies between the results of education in the area of biomedical sciences in the first year and the score for the admission criteria were described. However, as for the importance of gender as a predictive factor, we may refer to the rich resources of world literature which concern the stud- 
ies in the field of education. ${ }^{6,44-54}$ Generally, most of the researchers points to the fact that women do better during the course of studies than men. ${ }^{50}$ Moreover, in the field of medical education, it was observed that it is women who have greater chances of obtaining a diploma with distinction. ${ }^{46}$ As Ferguson $e t$ al. ${ }^{55}$ conclude on the basis of systematic revision of literature, it is recommended that gender be considered one of the important factors (independent variable) in predictive research concerning educating in medical directions. In the world literature from American studies, it can be seen that the majority of standardised tests used in entry examinations to universities, men do better than women. ${ }^{54}$ Yet the advantage of men over women in the field of mathematics reaches the value of 0.4 of standard effect. ${ }^{56}$ However, the results obtained while comparing the three admission criteria for pharmaceutical studies between men and women did not reveal any significant differences that would depend on gender. These results contrast with data obtained for comparison of GPA after the first year of studies, for which women reached higher values than men. This dependence is also reflected in the results of regression analysis in which male gender was pointed out to as a negative predictive factor $(\beta=-0.156)$. The above observations concerning the differences between the results of teaching achieved during the course of studies remain in accordance with the data published for the American studies. ${ }^{54}$

While analysing educational added value for the studied group of pharmacy students, it was observed that the assessment of relative progress is only slightly higher in case of women than it's in case of men, but it was not statistically relevant. As Zwick and Greif Green ${ }^{54}$ emphasises, a possibility of educational bias should be taken into account that would be beneficial for men. Researchers note the differences concerning the style of work between men and women while carrying out tests of MCQs type (multiple choice questions), which often are applied when measuring the effects of teaching at medical universities. ${ }^{57}$ Kessel and Linn ${ }^{56}$ note in their work that generally speaking, women need a long time for thinking a test question over because they present a greater reluctance towards simplifying questions and guessing answers. The in-depth analysis concerning inter-gender differences in the achieved teaching results suggests that they may be conditioned by a greater diligence, a more careful approach to the performed exercises, more dutiful attendance presented by women than men. According to the above thesis, women make greater progress in their education at university than men who have a similar academic background. ${ }^{54}$

Future achievements of female students may be underestimated in comparison to male ones if predicted on the basis of the results of a test entry exam. A slight difference in this case may result from an error of underestimation described above because the results of recruitment and evaluating students during their studies may measure the actual skills that women present in an inadequate way.

\section{CONCLUSION}

On the basis of the obtained results, it can be quite confidently said that the total score of the ranking points obtained by a candidate accepted to university has a significant influence on the result of teaching after the first year of studies at the Pharmacy Department. It is recommended that the predictive analyses be continued in consecutive years in order to establish permanent trends and to diagnose significant weaknesses of the currently used admission system for pharmaceutical studies at MUW. Also, the results of this work should be broadened by additional dependent variables such as learning outcomes in pharmaceutical subjects and GPA obtained throughout the whole course of studies. Ensuring a reliable and accurate assessment of candidates' input competences at the Pharmacy Department may lower the risk of attrition during the studies; in consequence minimize financial losses connected with educating students whose learning process will not be successfully completed.

\section{CONFLICT OF INTERESTS}

The authors declare that they have no conflict of interests.

\section{STUDY FUNDING}

This work was supported by the Medical University of Warsaw under number NZD/PM41/14 ("Young Investigator Grant”).

\section{REFERENCES}

1. Bartkowiak LE. Professional views of pharmacy faculty graduates. Wiad lek. 2006; 59(5-6): 303-10.

2. Wolkowitz AA. Multiple attempts on a nursing admissions examination: Effects on the total score. J Nurs Educ. 2011; 50(9): 493-501.

3. Allen DD, Bond CA. Pre-pharmacy predictors of success in pharmacy school: grade point averages, pharmacy college admissions test, communication abilities, and critical thinking skills. Pharmacotherapy 2001; 21(7): 842-9.
4. Cameron AJ, Mackeigan LD. Development and pilot testing of a multiple mini-interview for admission to a pharmacy degree program. Am J Pharm Educ. 2012; 76(1): 10.

5. Kidd RS, Latif DA. Traditional and novel predictors of classroom and clerkship success of pharmacy students. Am J Pharm Educ. 2003; 67(4): 109.

6. Mercer A, Puddey IB. Admission selection criteria as predictors of outcomes in an undergraduate medical course: a prospective study. Med Teach. 2011; 33(12): 997-1004. 
7. Janczukowicz J. Medical education in Poland. Med Teach. 2013; 35(7): 537-43.

8. Cox WC, Persky A, Blalock SJ. Correlation of the Health Sciences Reasoning Test with student admission variables. Am J Pharm Educ. 2013; 77(6): 118.

9. Hardinger KL, Schauner S, Graham M, Garavalia L. Admission predictors of academic dismissal for provisional and traditionally admitted students. Currents in Pharmacy Teaching and Learning. 2013; 5(1): 33-8.

10. Houglum JE, Aparasu RR, Delfinis TM. Predictors of academic success and failure in a pharmacy professional program. Am J Pharm Educ. 2005; 69(3): 43.

11. Kuncel NR, Crede M, Thomas LL, Klieger DM, Seiler SN, Woo SE. A metaanalysis of the validity of the Pharmacy College Admission Test (PCAT) and grade predictors of pharmacy student performance. Am J Pharm Educ. 2005; 69(3): 339-47.

12. McCall KL, MacLaughlin EJ, Fike DS, Ruiz B. Preadmission predictors of PharmD graduates' performance on the NAPLEX. Am J Pharm Educ. 2007; 71(1): 5 .

13. Meagher DG, Lin A, Perez CD. Predicting pharmacy students' performance from PCAT scores: a further analysis of predictive validity study data. Am J Pharm Educ. 2007; 71(5): 101.

14. Meagher DG, Lin A, Stellato CP. A predictive validity study of the Pharmacy College Admission Test. Am J Pharm Educ. 2006; 70(3): 53.

15. Meagher DG, Pan T, Perez CD. Predicting performance in the first-year of pharmacy school. Am J Pharm Educ. 2011; 75(5): 81.

16. Myers TL, DeHart RM, Vuk J, Zoran B. Prior degree status of student pharmacists: Is there an association with first-year pharmacy school academic performance? Currents in Pharmacy Teaching and Learning. 2013;5(5):490-3.

17. Renzi SE, Krzeminski MA, Sauberan MM, Brazeau DA, Brazeau GA. Prepharmacy years in college and academic performance in a professional program. Am J Pharm Educ. 2007; 71(4): 69.

18. Panczyk M, Gotlib J. Assessment of reliability, sensitivity, objectivity and validity of $\mathrm{MCQ}$ Pharmacology Exams as a potential output variable for predictive analysis. Indian J Pharm Educ Res. 2015; 49(1): 1-9.

19. Chisholm MA, Cobb HH, DiPiro JT, Lauthenschlager GJ. Development and validation of a model that predicts the academic ranking of first-year pharmacy students. Am J Pharm Educ. 1999; 63(4): 388-94.

20. Chisholm MA, Cobb HH, Kotzan JA. Significant factors for predicting academic success of first-year pharmacy students. Am J Pharm Educ. 1995; 59(4): 364-70

21. Atkinson J, Rombaut B. The PHARMINE study on the impact of the European Union directive on sectoral professions and of the Bologna declaration on pharmacy education in Europe. Pharm Pract. 2011; 9(4): 188-94.

22. Wilson S, Tordoff A, Beckett G. Pharmacy professionalism: A systematic analysis of contemporary literature (1998-2009). Pharm Educ. 2010; 10(1): 27-31.

23. Bush J. Entry characteristics and academic performance of students in a master of pharmacy degree program in the United Kingdom. Am J Pharm Educ. 2012; 76(7): 126.

24. Charupatanapong N, McCormick WC, Rascati KL. Predicting academic performance of pharmacy students: demographic comparisons. Am J Pharm Educ. 1994; 58(3): 262-8.

25. Fuller S, Horlen C, Cisneros R, Merz T. Pharmacy students' reading ability and the readability of required reading materials. Am J Pharm Educ. 2007; 71(6): 111.

26. Grillo JA, Latif DA, Stolte SK. The relationship between preadmission indicators and basic math skills at a new school of pharmacy. Ann Pharmacother 2001; 35(2): 167-72.

27. Hardigan PC, Lai LL, Arneson D, Robeson A. Significance of academic merit, test scores, interviews and the admissions process: A case study. Am J Pharm Educ. 2001; 65(1): 40-4.

28. Jungnickel PW. Grade-point averages and class rankings in evaluation of pharmacy residency applicants. Am J Health Syst Pharm. 2010; 67(18): 1500, 2.

29. Kelsch MP, Friesner DL. Evaluation of an interview process for admission into a school of pharmacy. Am J Pharm Educ. 2012; 76(2): 22

30. Kelsch MP, Friesner DL. The health sciences reasoning test in the pharmacy admissions process. Am J Pharm Educ. 2014; 78(1): 9

31. Latif DA. Including the assessment of nontraditional factors in pharmacy school admissions. Ann Pharmacother. 2005; 39(4): 721-6.

32. Lobb WB, Wilkin NE, McCaffrey DJ, Wilson MC, Bentley JP. The predictive utility of nontraditional test scores for first-year pharmacy student academic performance. Am J Pharm Educ. 2006; 70(6): 128.
33. McCall KL, Allen DD, Fike DS. Predictors of academic success in a doctor of pharmacy program. Am J Pharm Educ. 2006; 70(5): 106.

34. Meagher DG, Pan T, Wegner R, Olson AT, Overgaard SL, Mehle JJ. PCAT Reliability and Validity. 3rd ed. San Antonio: Pearson Executive Office; 2012.

35. Munson JW, Bourne DW. Pharmacy College Admission Test (PCAT) as a predictor of academic success. Am J Pharm Educ. 1976; 40(3): 237-9.

36. Popovich NG, Grieshaber LD, Losey MM, Brown CH. An evaluation of the PCAT examination based on academic performance. Am J Pharm Educ. 1977; 41(2): 128-32.

37. Schauner S, Hardinger KL, Graham MR, Garavalia L. Admission variables predictive of academic struggle in a PharmD program. Am J Pharm Educ. 2013; 77(1): 8.

38. Thomas MC, Draugalis JR. Utility of the Pharmacy College Admission Test (PCAT): Implications for Admissions Committees. Am J Pharm Educ. 2002; 66(1): 47-51.

39. Unni EJ, Zhang J, Radhakrishnan R, Smith KP, Bridgen CM, DeYoung MH, et al. Predictors of academic performance of pharmacy students based on admission criteria in a 3-year pharmacy program. Currents in Pharmacy Teaching and Learning 2011; 3(3): 192-8.

40. Vongvanith VV, Huntington SA, Nkansah NT. Diversity characteristics of the 2008-2009 pharmacy college application service applicant pool. Am J Pharm Educ. 2012; 76(8): 151.

41. Dolata R, Pokropek A. Analiza metod szacowania edukacyjnej wartości dodanej dla szkół kończących się matura. In: Dolata R, editor. Edukacyjna wartość dodana jako metoda ceny efektwyności nauczania na podstawie wyników egzaminów zewnętrznych. Warszawa: Centralna Komisja Egzaminacyjna; 2007.

42. Niemierko B. Pomiar wyników kształcenia. Warszawa: Wydawnictwo Szkolne i Pedagogiczne; 1999.

43. Niemierko B. Diagnostyka edukacyjna. Warszawa: Wydawnictwo Naukowe PWN; 2009.

44. Ferguson E, Sanders A. Predictive validity of personal statements and the role of the five-factor model of personality in relation to medical training. $J$ Occup Organ Psychol. 2000; 73(3): 321-44.

45. Martin IG, Stark P, Jolly B. Benefiting from clinical experience: the influence of learning style and clinical experience on performance in an undergraduate objective structured clinical examination. Med Educ. 2000; 34(7): 30-4

46. McDonough CM, Horgan A, Codd MB, Casey PR. Gender differences in the results of the final medical examination at University College Dublin. Med Educ. 2000; 34(1): 30-4.

47. McManus IC, Richards P. Prospective survey of performance of medical students during preclinical years. BMJ (Clinical research ed). 1986; 293(6539): 124-7.

48. McManus IC, Richards P, Winder BC, Sproston KA. Final examination performance of medical students from ethnic minorities. Med Educ. 1996; 30(3): 195-200.

49. Oggins J, Inglehart M, Brown DR, Moore W. Gender differences in the prediction of medical students' clinical performance. J Am Med Womens Assoc. 1988; 43(6): 171-5.

50. Pai MRSM, Sanji N, Pai PG, Kotian S. Comparative assessment in pharmacology multiple choice questions versus essay with focus on gender differences. J Clin Diagn Res. 2010; 4(3): 2515-20.

51. Ramsbottom-Lucier M, Johnson MM, Elam CL. Age and gender differences in students' preadmission qualifications and medical school performances. Acad Med. 1995; 70(3): 236-9.

52. Weinberg E, Rooney JF. The academic performance of women students in medical school. JMed Educ. 1973; 48(3): 240-7.

53. Win R, Miller PW. The Effects of Individual and School Factors on University Students' Academic Performance. Australian Econ Rev. 2005; 38(1): 1-18.

54. Zwick R, Greif Green J. New Perspectives on the Correlation of SAT Scores, High School Grades, and Socioeconomic Factors. J Educ Meas. 2007; 44(1): 23-45.

55. Ferguson E, James D, Madeley L. Factors associated with success in medical school: systematic review of the literature. BMJ. 2002; 324(7343): 952-7.

56. Kessel C, Linn MC. Grades or Scores: Predicting Future College Mathematics Peflormance. Educ Meas. 1996; 15(4): 10-4.

57. Ben-Shakhar G, Sinai Y. Gender Differences in Multiple-Choice Tests: The Role of Differential Guessing Tendencies. J Educ Meas. 1991; 28(1): 23-35. 